\title{
INSERÇÃO DOS JOVENS NO MERCADO DE TRABALHO EM TEMPOS DE CRISE ${ }^{1,2}$
}

\author{
Carlos Henrique Corseuil ${ }^{3}$ \\ Maíra Franca ${ }^{4}$
}

\section{INTRODUÇÃO E CONTEXTUALIZAÇÃO}

Um início promissor no mercado de trabalho é um desafio difícil enfrentado pelos jovens trabalhadores, mesmo em períodos em que a atividade econômica, e especificamente o mercado de trabalho, apresenta bom desempenho. A literatura especializada também mostra que a deterioração no cenário econômico afeta esses indivíduos de forma particularmente intensa. Mais do que isso, há evidências de que os efeitos de períodos de recessão na inserção dos jovens no mercado de trabalho perduram muitos anos além do fim do período recessivo.

Este texto tem por objetivo analisar a inserção dos jovens no mercado de trabalho brasileiro entre 2013 e 2020, enfocando nas mudanças registradas em dois episódios de forte retração econômica, sendo o primeiro deles em torno de 2015-2016 e o segundo no corrente ano de 2020, em decorrência da pandemia da Covid-19. Toda nossa análise será baseada em dados da Pesquisa Nacional por Amostra de Domicílios (PNAD) Contínua do Instituto Brasileiro de Geografia e Estatística (IBGE). ${ }^{5}$

As evidências neste tipo de estudo tendem a se resumir a aumentos na taxa de desemprego mais intensos para jovens do que para adultos em contextos recessivos. Nesse sentido, pretendemos mostrar um quadro mais amplo do que ocorre com as condiçóes de inserção dos jovens no mercado de trabalho em cenários de recessão. Em primeiro lugar, analisaremos o conjunto mais amplo de indicadores para complementar a informação fornecida pela evolução do desemprego. Isso mostra-se particularmente importante na análise de 2020, quando os efeitos da forte retração econômica não podem ser capturados pela evoluçáo do desemprego. Em segundo lugar, não nos limitaremos a acompanhar a evolução de estoques de trabalhadores jovens em distintos estados no mercado de trabalho. Faremos uso de informaçóes longitudinais para explorar os fluxos de trabalhadores entre esses diferentes estados de forma a ter um melhor entendimento dos determinantes dos movimentos nos respectivos estoques.

1. DOI: http://dx.doi.org/10.38116/bmt70/dossiea1

2. Este trabalho resume um esforço analítico sobre o tema que se iniciou em 2018 e se beneficiou de comentários recebidos em quatro oficinas de trabalho com participações de representantes do Ipea, da Organização Internacional do Trabalho (OIT), do Centro Brasileiro de Análise e Planejamento (Cebrap) e da Secretaria de Trabalho do Ministério da Economia.

3. Técnico de planejamento e pesquisa na Diretoria de Estudos e Políticas Sociais (Disoc) do Ipea. E-mail: <carlos.corseuil@ipea.gov.br>. 4. Pesquisadora do Subprograma de Pesquisa para o Desenvolvimento Nacional (PNPD) na Disoc/lpea. E-mail:<maira.franca@ipea.gov.br>. 5. Dados disponíveis em: <https://bit.ly/33SWrnj>. 


\section{A PRIMEIRA RECESSÃO}

Em 2014, o Brasil entrou em uma recessão que trouxe reflexos para o mercado de trabalho ao longo de 2015 e 2016. Nesse período, houve uma queda abrupta na parcela de jovens ocupados, como atesta o gráfico 1 . No primeiro trimestre de 2017, a parcela de jovens ocupados atingiu seu mínimo, no período analisado, com a marca de $47,3 \%$; em comparação, no primeiro trimestre de 2015, essa parcela representava $53,1 \%$ dos jovens. Houve, portanto, uma queda de cerca de 6 pontos percentuais (p.p.) nesse período de dois anos. O gráfico 1 sugere uma contrapartida na parcela de jovens desempregados que passa de $9,4 \%$, no primeiro trimestre de 2015 , para $15,7 \%$, no primeiro trimestre de 2017 .

\section{GRÁFICO 1}

Proporção trimestral de ocupados e de desempregados na população jovem (2013-2018) (Em \%)

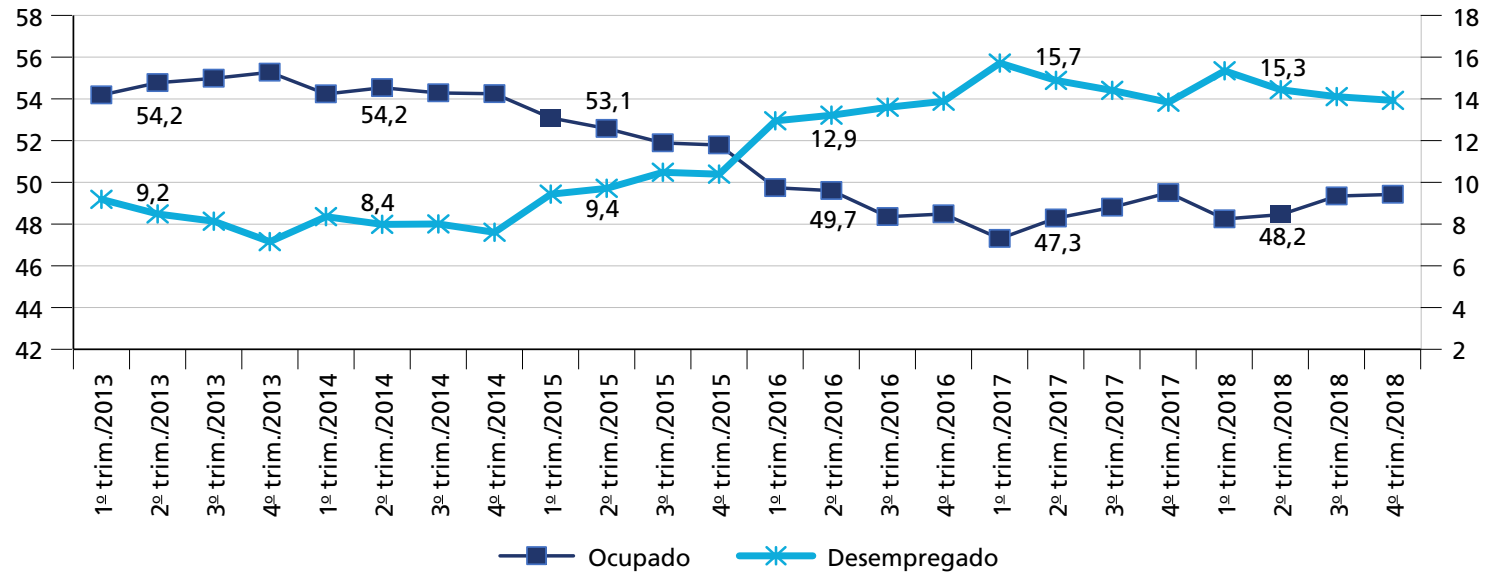

Fonte: PNAD Contínua/IBGE.

Elaboração dos autores.

Tal compensação entre os movimentos nas parcelas de ocupados e desempregados manteve os quantitativos da força de trabalho (composta por esses dois estados) e de inativos praticamente inalterados nesse período. No entanto, há uma mudança de composição importante a ser notada no grupo dos inativos, com um aumento bastante expressivo da parcela de jovens desalentados. ${ }^{6}$ A parcela desses jovens, que estariam em condiçóes de trabalhar, mas nem sequer procuram por um trabalho por não acreditarem nas chances de conseguir, passa de $4,1 \%$, no primeiro trimestre de 2015, para 10,8\%, no primeiro trimestre de 2017, conforme ilustrado no gráfico 2.

6. De acordo com IBGE (2020), os desalentados são as pessoas fora da força de trabalho na semana de referência que estavam disponíveis para assumir um trabalho, mas não tomaram providência para conseguir emprego no período de referência por não: $i$ ) ter conseguido trabalho adequado; ii) ter experiência profissional ou qualificação; iii) haver trabalho na localidade em que residia; ou iv) conseguir trabalho por ser considerado muito jovem ou muito idoso. 
GRÁFICO 2

Proporção trimestral de desalentados em relação à população não economicamente ativa (2013-2018)

(Em \%)

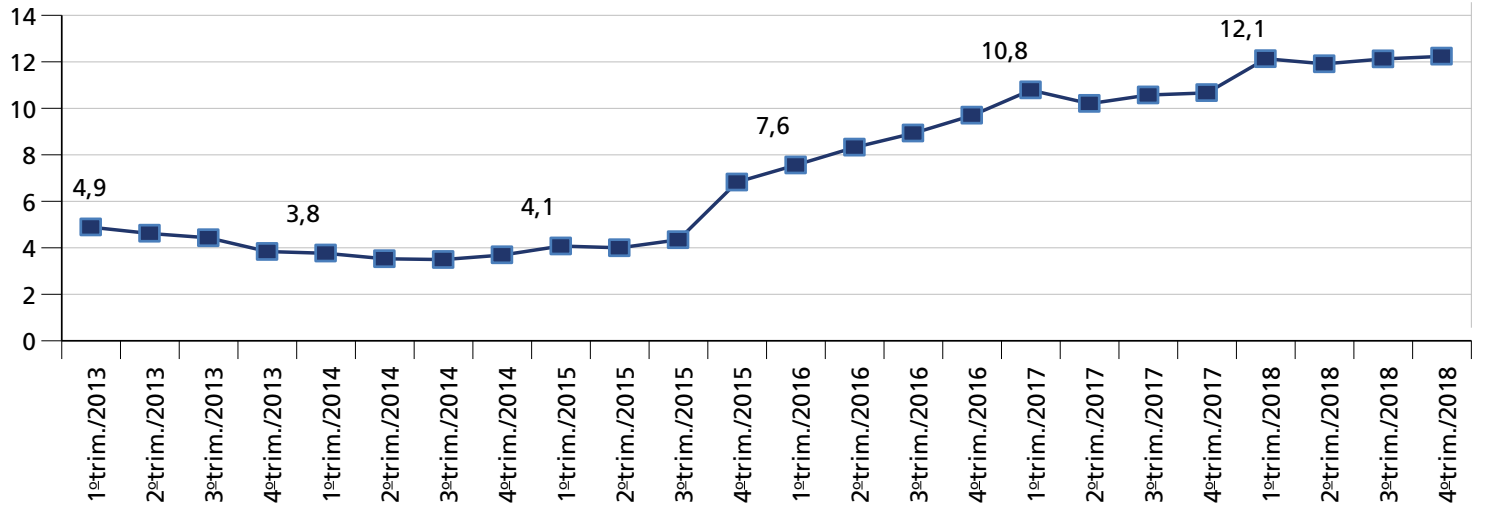

Fonte: PNAD Contínua/IBGE.

Elaboração dos autores.

A análise dos fluxos de trabalhadores jovens que se encontravam desempregados de acordo com seus destinos após um trimestre oferece importantes pistas para compreender os determinantes do aumento do desemprego e do desalento entre os jovens. O gráfico 3 mostra que o fluxo de saída do desemprego para a ocupação cai de $31,1 \%$ para $22,5 \%$ entre os primeiros trimestres de 2015 a 2017. A taxa de permanência no desemprego entre dois trimestres consecutivos, por sua vez, aumenta sensivelmente de 39,4\%, no primeiro trimestre de 2015, para 51,0\%, no primeiro trimestre de 2017.

Ou seja, os jovens ficam retidos no desemprego e isso pode vir a desencorajar uma parcela que decide nem procurar trabalho.

GRÁFICO 3

Destino para os desempregados após um trimestre (2013-2018) (Em \%)

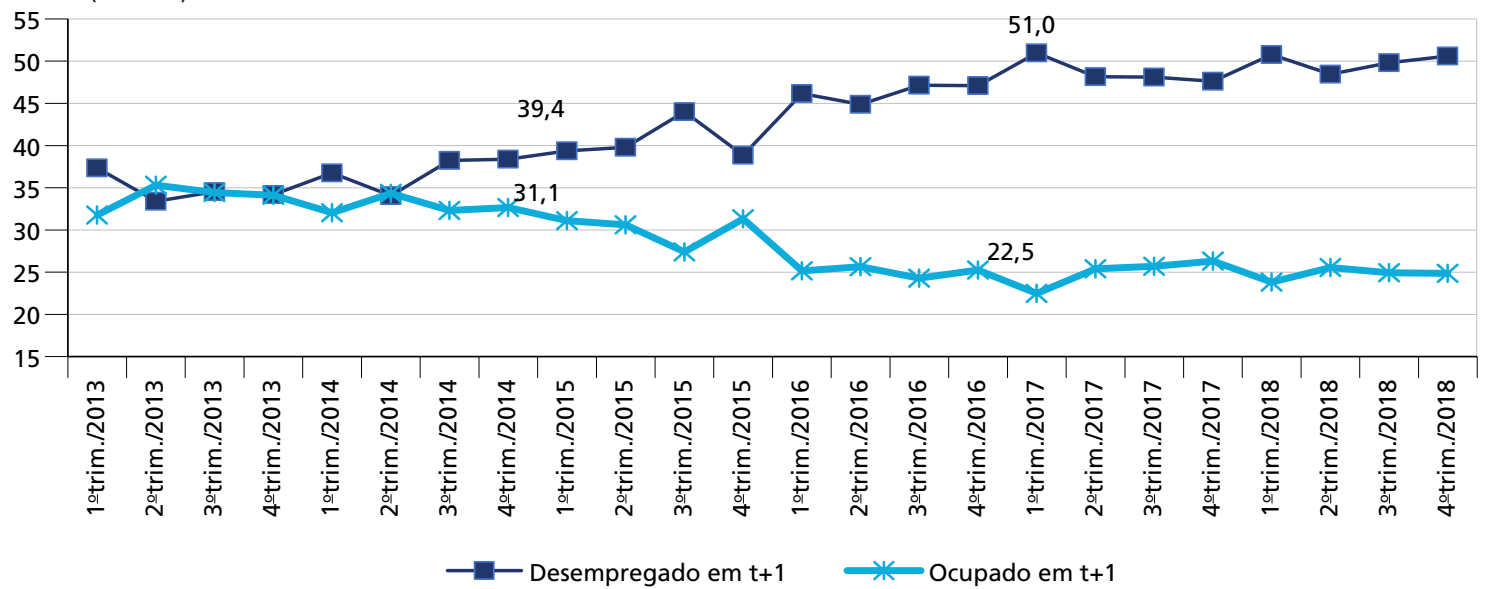

Fonte: PNAD Contínua/IBGE.

Elaboração dos autores. 
O gráfico 4 indica que cresce o fluxo de entrada de jovens no desemprego, tanto provenientes do emprego como da inatividade. Porém, esses aumentos são menos intensos do que a elevação na permanência no desemprego.

GRÁFICO 4

Transição para desemprego após um trimestre (2013-2018)

(Em \%)

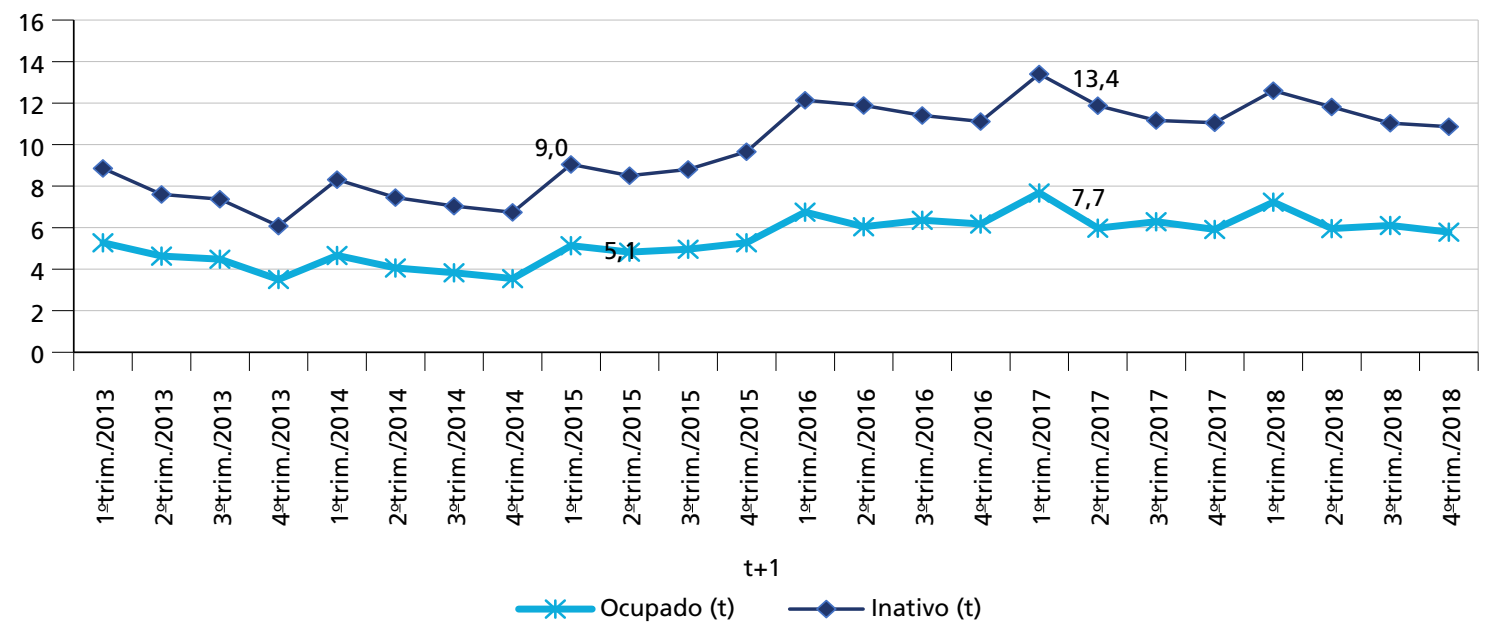

Fonte: PNAD Contínua/IBGE.

Elaboração dos autores.

Além da maior dificuldade dos jovens para sair do desemprego, aqueles que conseguiam um emprego ocupavam postos associados a menores salários e/ ou a menores níveis de produtividade. Evidências na literatura, como Cruces, Ham e Violas (2012), alertam para os riscos desse tipo de inserção afetar a trajetória dos jovens por muitos anos.

\section{A CHEGADA DA PANDEMIA DA COVID-19}

Em março de 2020, a Organização Mundial da Saúde (OMS) declarou a Covid-19, doença causada pelo novo coronavírus, Sars-COV-2, como pandemia e recomendou medidas de distanciamento social. Em um período muito curto, a atividade econômica foi severamente atingida, o que, por sua vez, também afetou o mercado de trabalho em todo o mundo. No Brasil, o produto interno bruto (PIB) caiu quase $10 \%$ no segundo trimestre de 2020 em relação ao trimestre anterior. De acordo com dados da PNAD Contínua do IBGE, 8,9 milhóes de pessoas perderam seus postos de trabalho entre abril e junho, em relação ao período de janeiro a março de 2020.

O gráfico 5 apresenta a evolução das taxas de ocupação e inatividade entre os jovens brasileiros. A proporção de jovens ocupados, que era de 48,6\%, no primeiro trimestre de 2020, atingiu 41,4\% já no trimestre seguinte, o que significa uma queda de 7,2 p.p. em apenas um trimestre. Essa queda na ocupação foi mais acentuada do que a redução de 5,8 p.p. registrados entre os primeiros trimestres de 2015 a 2017. 
GRÁFICO 5

Evolução trimestral das taxas de ocupação e inatividade dos jovens (2019-2020) (Em \%)

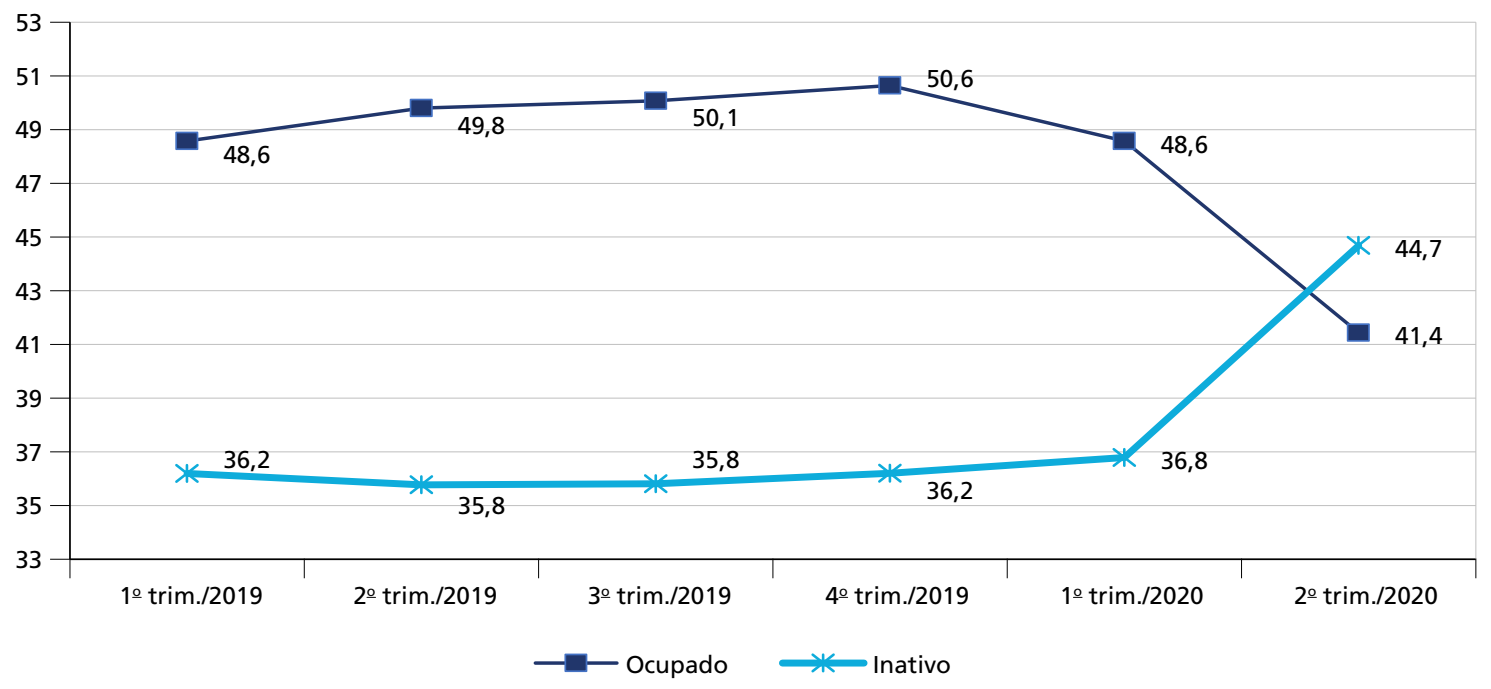

Fonte: PNAD Contínua/IBGE.

Elaboração dos autores.

A contrapartida da queda acentuada da taxa de ocupação foi o aumento da proporção de jovens fora da força de trabalho, que foi de $36,8 \%$, no primeiro trimestre de 2020 , e atingiu $44,7 \%$, no segundo trimestre de 2020. Essa queda na participação de cerca de 8 p.p. em apenas um trimestre é algo sem precedentes no período coberto pela PNAD Contínua, algo que também já foi destacado para o agregado da população.

A tendência de queda na ocupação e aumento da inatividade no segundo trimestre de 2020 ocorreu para todos os recortes socioeconômicos, como pode ser observado nas tabelas A.1 e A.2 do apêndice A. Mais de $50 \%$ das mulheres jovens se encontravam fora da força de trabalho no segundo trimestre de 2020, um aumento de 9,2 p.p. em relaçáo à taxa do segundo trimestre de 2019. Os homens apresentaram um aumento de 8,5 na proporção de inativos no mesmo período, chegando a $38 \%$ de inativos no último trimestre. No recorte regional, destaca-se o aumento de 10 p.p. na população de jovens inativos da regiáo Nordeste, cujo percentual chegou a 56\% no segundo trimestre de 2020.

Com a interrupção das atividades econômicas e o fechamento de milhares de vagas de emprego, era esperado que aumentasse a parcela de jovens na condição de desalento, isto é, que não procuraram emprego, mas estavam disponíveis para trabalhar. À primeira vista, os dados da PNAD Contínua indicam não ter ocorrido um aumento na parcela de jovens inativos na condição de desalentados. Essa parcela se manteve em $11,7 \%$ tanto no primeiro como no segundo trimestre de 2020, de acordo com a linha de baixo no gráfico 6 . 
GRÁFICO 6

Evolução trimestral do percentual de desalentados (2019-2020)

(Em \%)

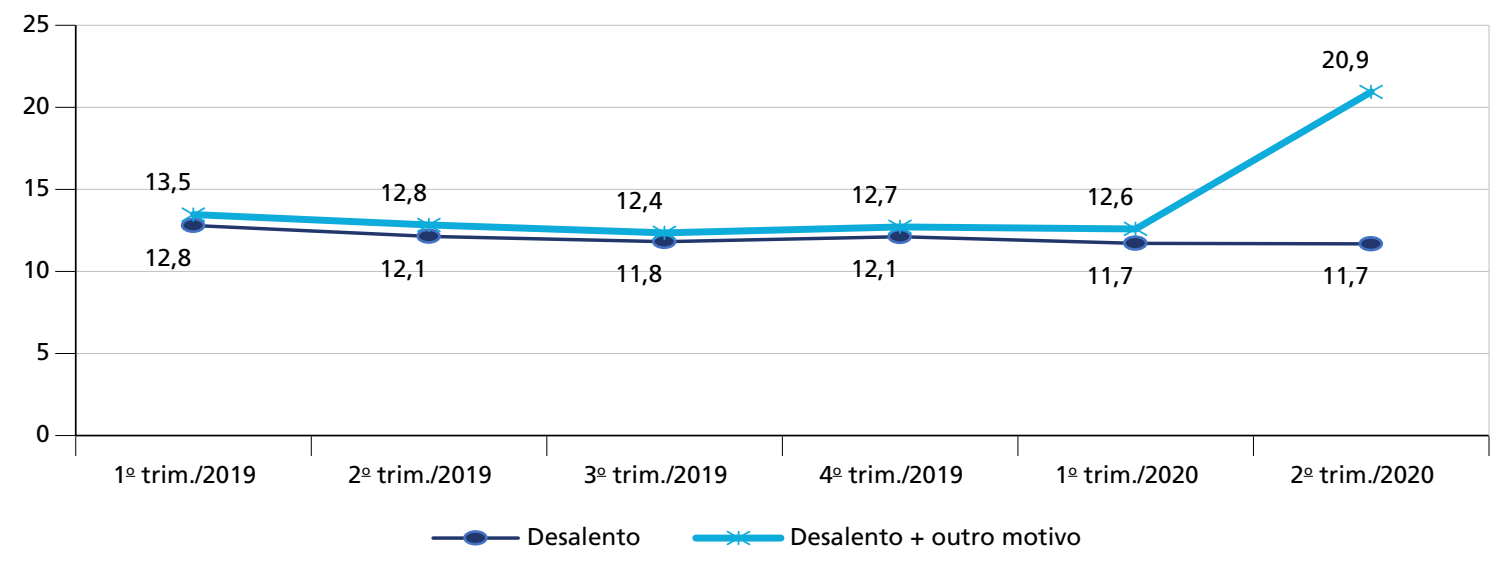

Fonte: PNAD Contínua/IBGE.

Elaboração dos autores.

No entanto, é provável que o questionário da PNAD Contínua não esteja captando adequadamente o aumento do desalento decorrente da pandemia. Com base nos dados da PNAD Covid-19 do IBGE, em maio e junho de 2020, cerca de $30 \%$ dos jovens fora da força de trabalho declararam não ter buscado trabalho especificamente devido à pandemia (por motivos de isolamento, quarentena ou distanciamento social), embora gostariam de ter trabalhado na semana de referência. ${ }^{7}$ A PNAD Contínua não inclui, em seu questionário, a pandemia como uma justificativa para se desistir de buscar trabalho no período de referência. $\mathrm{Na}$ classificação do IBGE, os desalentados são aqueles que não buscaram trabalho por não ter experiência profissional ou qualificação, por ser considerado muito jovem ou por não haver trabalho na localidade.

Mas existe uma categoria residual que capta outros motivos não especificados pelas demais categorias. Acreditamos que o jovem desalentado devido à pandemia pode especificar essa categoria residual como motivo para a não procura por trabalho. A linha de cima, no gráfico 6, parece confirmar essa hipótese, pois aparece um aumento de 8 p.p., no segundo trimestre de 2020, na parcela de inativos que incorpora a categoria outro motivo aos demais motivos da não procura por trabalho associados ao desalento.

Voltando ao aumento de cerca de 8 p.p. da proporçáo de jovens fora da força de trabalho em 2020, vale notar que é maior do que a queda na taxa de ocupação, o que significa que parte da população de desempregados também deixou a força de trabalho. Esse fato é confirmado pelo gráfico 7 , que mostra que a parcela de jovens desempregados passa de $14,6 \%$, no primeiro trimestre de 2020, para 13,9\%, no segundo trimestre de 2020. Aqui temos outra diferença marcante em relação ao ajuste no mercado de trabalho dos jovens no período 2015-2016, quando a parcela de jovens desempregados sobe consideravelmente.

7. Mais informações em: <https://bit.ly/371hR3L > 
GRÁFICO 7

Proporção trimestral de desempregados na população jovem (2019-2020)

(Em \%)

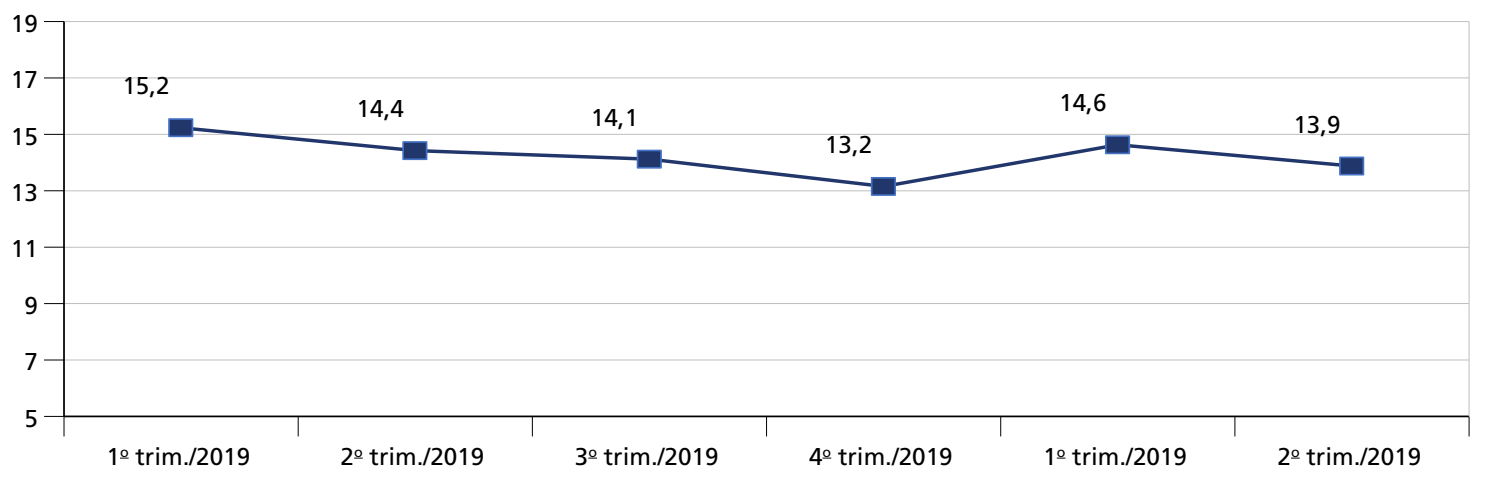

Fonte: PNAD Contínua/IBGE.

Elaboração dos autores.

Os gráficos 8 e 9 indicam que o fator determinante para o decréscimo da parcela de jovens desempregados não foi um aumento no fluxo de saída. Pelo contrário, o gráfico 8 aponta um aumento expressivo na retenção dos jovens no estado de desempregado. Entre o primeiro e o segundo trimestre de 2020, a parcela de jovens que estava desempregada em um trimestre, e continua assim no trimestre seguinte, sobe de 50,2\% para 62,7\%. Contudo, há uma diminuição ainda mais expressiva no fluxo de entrada dos jovens no desemprego, principalmente aqueles provenientes da inatividade, conforme atestado pelo gráfico 9. No primeiro trimestre de 2020, $12,3 \%$ dos jovens fora da força de trabalho transitavam para o desemprego. Esse fluxo cai para $4,7 \%$ no segundo trimestre de 2020 .

GRÁFICO 8

Permanência no desemprego após um trimestre (2019-2020)

(Em \%)

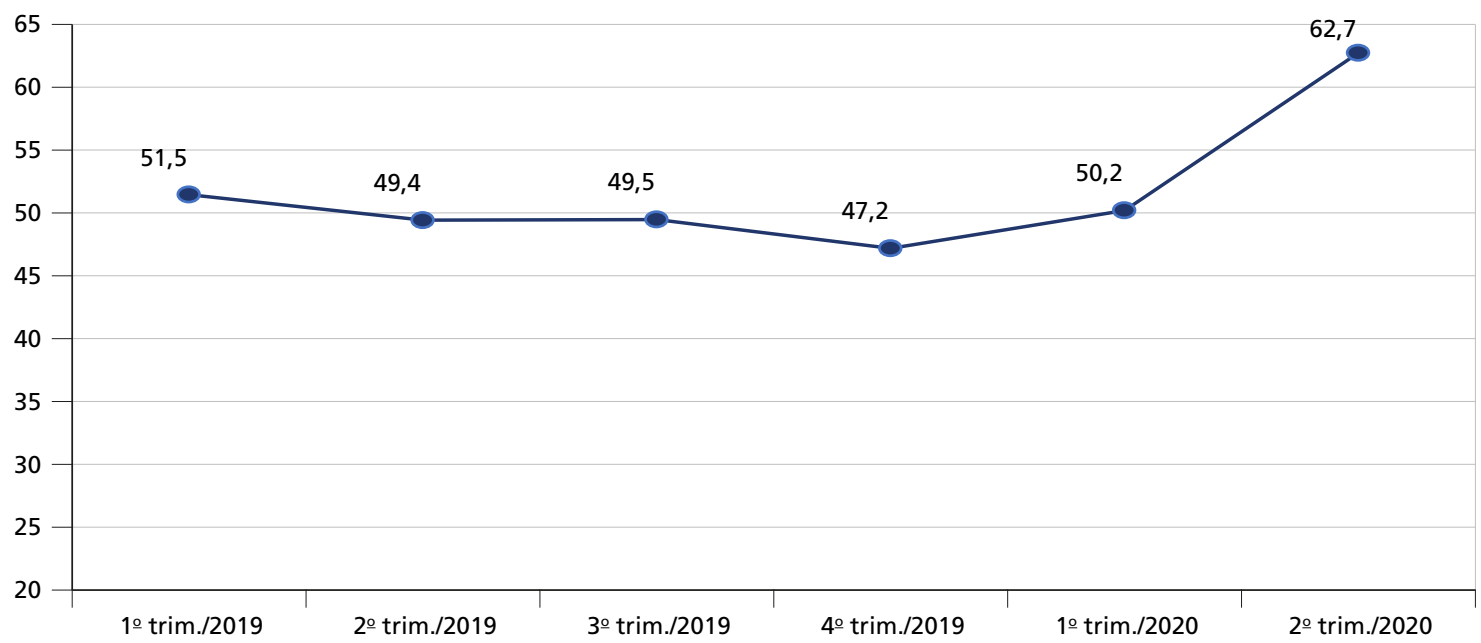

Fonte: PNAD Contínua/IBGE.

Elaboração dos autores. 
GRÁFICO 9

Transição para o desemprego após um trimestre (2019-2020)

(Em \%)

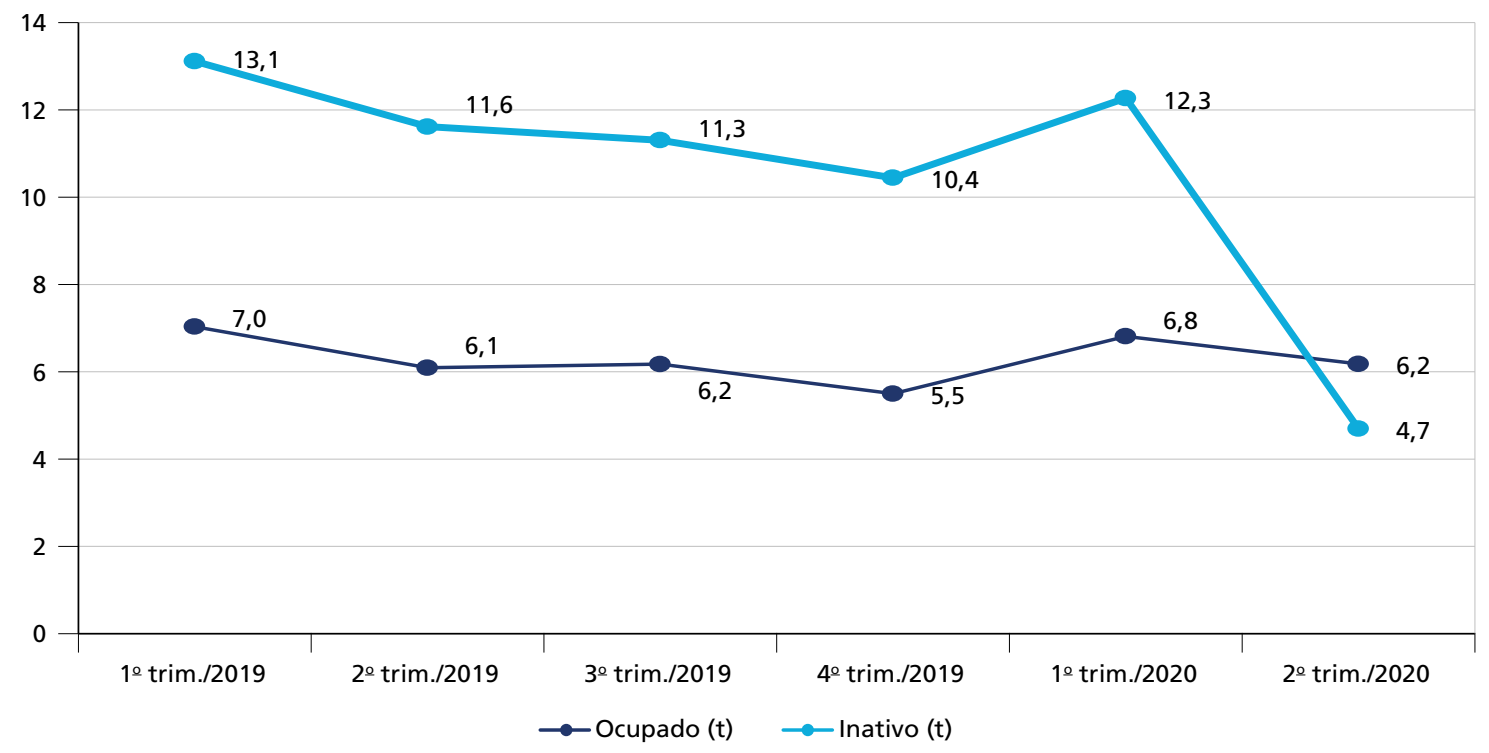

Fonte: PNAD Contínua/IBGE.

Elaboração dos autores.

Em suma, embora tenhamos quedas expressivas na parcela de ocupados em ambos os episódios de recessão aqui analisados, há uma diferença marcante em relação ao estado do mercado de trabalho que passa a absorver mais os jovens. Esse papel é desempenhado pelo desemprego no primeiro episódio de recessão, mas claramente não é o caso em 2020, quando a inatividade é que passa a ser o estado do mercado de trabalho que absorve os jovens. Há, portanto, um maior distanciamento dos jovens com o mercado de trabalho atualmente, quando comparado com o período 2015-2017. Isso motiva preocupaçóes com a possibilidade de um período mais longo de afastamento do jovem do mercado de trabalho, que, por sua vez, pode vir a comprometer sua trajetória profissional futura, conforme mencionado na seção 1 .

\section{CONSIDERAÇÕES FINAIS}

Um início promissor no mercado de trabalho é um desafio difícil enfrentado pelos jovens trabalhadores, mesmo em períodos em que a atividade econômica, e especificamente o mercado de trabalho, apresenta bom desempenho. A literatura especializada também mostra que a deterioração no cenário econômico traz efeitos, tanto estáticos como dinâmicos, particularmente preocupantes para os jovens (Gregg e Tominey, 2005; Eliason e Storrie, 2006).

Avanços recentes no campo teórico propóem estabelecer um elo entre esses dois fatos, ao sugerir um motivo para maiores barreiras ao ingresso no mercado de trabalho, para os jovens que sejam sensíveis ao ciclo econômico. Dessa forma, explica-se também que a recessão pode ampliar essa barreira potencial à inserção dos jovens no mercado de trabalho. 
A assimetria de informação sobre a produtividade potencial dos trabalhadores, quando um empregador encontra um empregado potencial, seria o elemento-chave para entender o cenário já apresentado. Em geral, os empregadores confiam nas informaçóes sobre as experiências anteriores do trabalhador no mercado de trabalho para inferir sua produtividade potencial. Quanto menos informaçôes disponíveis, maior é o risco enfrentado pelo empregador ao contratar um trabalhador que pode não ter um desempenho satisfatório. Nesse sentido, contratar um jovem seria mais arriscado, pois eles tendem a ter baixos níveis (se houver) de experiência no mercado de trabalho. Isso, portanto, explicaria as maiores dificuldades encontradas pelos jovens, independentemente do contexto econômico.

Essa questão da falta de experiência pode dificultar ainda mais a inserçăo dos jovens no mercado de trabalho em contextos recessivos. Huckefeldt (2016) propóe uma teoria em que o processo de contrataçáo se torna mais seletivo durante as recessôes, mecanismo que atinge principalmente as perspectivas dos jovens trabalhadores no decorrer desses períodos, ampliando a barreira mencionada à integraçáo dos jovens no mercado de trabalho. O elemento-chave de sua teoria encontra suporte em estudos empíricos sobre a colocação de vagas e recessōes, como Modestino, Shoag e Ballance (2019), que confirmam que a exigência de educaçáo e experiência aumentou significativamente em empregos anunciados nos Estados Unidos durante a grande recessão de 2008-2009.

Se nenhuma intervenção for implementada para contrabalançar esse mecanismo, o desemprego juvenil (ou, mais geralmente, a taxa de não emprego) aumentará desproporcionalmente, o que, por sua vez, aumentará os efeitos cicatrizantes, comprometendo as perspectivas futuras de um número excessivo de jovens trabalhadores.

As evidências que apresentamos sobre como se modificam as possibilidades de inserção dos jovens no mercado de trabalho em dois episódios recessivos confirmam um quadro de deterioração e afastamento dos jovens do mercado de trabalho, sobretudo agora em 2020, por conta da pandemia da Covid-19. Se o arcabouço teórico exposto nesta seção captar de fato os principais determinantes para explicar o que ocorre no mercado de trabalho dos jovens, há que se pensar em iniciativas que reconectem o maior contingente de jovens, e o mais rápido possível, ao mercado de trabalho.

\section{REFERÊNCIAS}

CRUCES, G.; HAM, A.; VIOLAS, M. Scarring effects of youth unemployment and informality: evidence from Argentina and Brazil. 2012. Mimeografado.

ELIASON, M.; STORRIE, D. Lasting or Latent Scars? Swedish evidence on the long-term effects of job Displacement. Journal of Labor Economics, n. 24, v. 4, p. 831- 856, 2006.

GREGG, P.; TOMINEY, E. The wage scar from male youth unemployment. Labour Economics, v. 12, p. 487-509, 2005.

HUCKFELDT, C. Understanding the scarring effect of recessions. Report. Economics Department, Cornell University, 2016. 
IBGE - INSTITUTO BRASILEIRO DE GEOGRAFIA E ESTATÍSTICA. Pesquisa Nacional por Amostra de Domicílios Contínua. Divulgação Especial. Medidas de Subutilizaçáo da Força de Trabalho no Brasil. Rio de Janeiro: IBGE, 2020.

MODESTINO, A. S.; SHOAG, D.; BALLANCE, J. Upskilling: do employers demand greater skill when workers are plentiful? The Review of Economics and Statistics, p. 1-46, 2019. 


\section{APÊNDICE A}

TABELA A.1

Taxa de ocupação dos jovens por grupo socioeconômico (2019-2020) (Em \%)

\begin{tabular}{|c|c|c|c|c|c|c|c|}
\hline \multirow{2}{*}{ Trimestre/ano } & \multicolumn{4}{|c|}{2019} & \multicolumn{2}{|c|}{2020} & \multirow{2}{*}{$\begin{array}{c}\text { Variação (2ํ tri. 2020- } \\
\text { 2ำ tri. 2019) }\end{array}$} \\
\hline & 10 tri. & 2o tri. & 3o tri. & 40 tri. & 10 tri. & 2o tri. & \\
\hline Todos & 48,6 & 49,8 & 50,1 & 50,6 & 48,6 & 41,4 & $-8,4$ \\
\hline \multicolumn{8}{|c|}{ Sexo } \\
\hline Homens & 55,6 & 56,9 & 57,3 & 57,9 & 56,0 & 48,1 & $-8,9$ \\
\hline Mulheres & 41,4 & 42,6 & 42,7 & 43,4 & 41,1 & 34,9 & $-7,7$ \\
\hline \multicolumn{8}{|c|}{ Cor } \\
\hline Brancos e amarelos & 52,8 & 54,1 & 54,2 & 54,8 & 52,6 & 46,3 & $-7,8$ \\
\hline Pretos, pardos e índios & 45,8 & 47,0 & 47,4 & 48,0 & 46,0 & 38,2 & $-8,8$ \\
\hline \multicolumn{8}{|c|}{ Escolaridade } \\
\hline Fundamental incompleto & 36,1 & 34,9 & 33,7 & 33,1 & 34,6 & 27,2 & $-7,8$ \\
\hline Fundamental completo & 32,7 & 33,9 & 34,0 & 34,9 & 31,5 & 25,0 & $-9,0$ \\
\hline Médio completo & 60,2 & 62,5 & 63,8 & 64,4 & 60,2 & 52,9 & $-9,6$ \\
\hline \multicolumn{8}{|c|}{ Região } \\
\hline Norte & 41,5 & 43,2 & 44,0 & 43,9 & 42,2 & 36,4 & $-6,7$ \\
\hline Nordeste & 39,5 & 40,5 & 40,2 & 40,6 & 38,6 & 31,3 & $-9,2$ \\
\hline Sudeste & 52,1 & 53,7 & 53,8 & 54,9 & 52,4 & 44,7 & $-9,0$ \\
\hline Sul & 59,3 & 60,0 & 61,0 & 61,7 & 60,2 & 54,9 & $-5,2$ \\
\hline Centro-Oeste & 54,0 & 54,8 & 55,4 & 54,6 & 53,3 & 46,4 & $-8,4$ \\
\hline
\end{tabular}

Fonte: Pesquisa Nacional por Amostra de Domicílios (PNAD) Contínua do Instituto Brasileiro de Geografia e Estatística (IBGE). Disponível em: <https://bit.ly/33SWrnj>.

Elaboração dos autores.

TABELA A.2

Taxa de inatividade por grupo socioeconômico (2019-2020)

(Em \%)

\begin{tabular}{|c|c|c|c|c|c|c|c|}
\hline \multirow{2}{*}{ Trimestre/ano } & \multicolumn{4}{|c|}{2019} & \multicolumn{2}{|c|}{2020} & \multirow{2}{*}{$\begin{array}{c}\text { Variação (2 tri./2020- } \\
\text { 2o tri./2019) }\end{array}$} \\
\hline & 10 tri. & 20 tri. & 3o tri. & $4^{\circ}$ tri. & 10 tri. & 20 tri. & \\
\hline Todos & 36,2 & 35,8 & 35,8 & 36,2 & 36,8 & 44,7 & 8,9 \\
\hline \multicolumn{8}{|c|}{ Sexo } \\
\hline Homens & 29,7 & 29,3 & 29,4 & 29,9 & 30,2 & 37,8 & 8,5 \\
\hline Mulheres & 42,8 & 42,3 & 42,3 & 42,5 & 43,3 & 51,5 & 9,2 \\
\hline \multicolumn{8}{|c|}{ Cor } \\
\hline Brancos e amarelos & 33,5 & 33,3 & 33,7 & 33,3 & 34,2 & 41,3 & 8,0 \\
\hline Pretos, pardos e índios & 38,0 & 37,4 & 37,2 & 38,0 & 38,4 & 46,9 & 9,5 \\
\hline \multicolumn{8}{|c|}{ Escolaridade } \\
\hline Fundamental incompleto & 51,9 & 53,2 & 54,5 & 56,2 & 53,3 & 61,4 & 8,2 \\
\hline
\end{tabular}


(Continua)

\begin{tabular}{lccccccc}
\hline \multirow{2}{*}{ Trimestre/ano } & \multicolumn{9}{c}{2019} & \multicolumn{2}{c}{2020} & Variação (20 tri./2020- \\
20 tri./2019)
\end{tabular}

Fonte: PNAD Contínua/IBGE.

Elaboração dos autores. 